\title{
Design of intelligent home environment monitoring system
}

\author{
Mimi Wang ${ }^{1, a,}$, Fengping Cao ${ }^{1, b}$ \\ ${ }^{1}$ Southeast University Chengxian College, Dongda Road No. 6, Nanjing, China \\ ayimi0516@163.com, ${ }^{\mathrm{b}}$ 54346096@qq.com, \\ *corresponding author
}

Keywords: Intelligent Home; MCU; DHT11; MQ-2.

\begin{abstract}
At present, the rapid development of science and technology to improve people's quality of life requirements, the traditional home to smart home development has become an inevitable trend. But the development of smart home in the country compared to abroad, or far less. In the production and manufacturing level, penetration and practicality and other aspects of the gap is obvious. Therefore, the study of intelligent home system is far-reaching. The design focuses on the environmental monitoring of the intelligent home system. The STC89C52RC microcontroller is the core of the control. The main environmental parameters (such as temperature, humidity and smoke concentration) are monitored and displayed. The DHT11 temperature and humidity sensor And MQ-2 smoke sensor and other components as a research basis, the use of multi-sensor fusion technology for targeted design. The system to achieve a liquid crystal display, temperature and humidity detection, smoke concentration detection, LED and buzzer alarm function, key adjustment and other functions. After the test shows that the system can work in the long term to ensure the accuracy of the parameters, with simple and feasible operation, the parameters can be timely display and so on.
\end{abstract}

\section{Introduction}

The growth of the century economy has brought about the improvement of material requirements, and the backward material living standard gradually contradicted the level of social development. How to improve the living environment, improve the quality of life is a problem that a lot of people urgently need to solve. Compared with foreign countries, the development of intelligent home system is relatively backward, so study intelligent home system becomes very meaningful ${ }^{[1]}$. The design is designed to produce a smart home environment monitoring system that manufactures a low-cost, low-power, easy-to-use, and family life.

\section{The Design Strategy}

The design uses the principle of structural design, the design of intelligent home environment monitoring system is divided into seven modules: temperature and humidity monitoring module, smoke monitoring module, data acquisition module, display module, alarm module, key adjustment module. To single-chip as the core, according to the intelligent home environment monitoring system design requirements, the use of various types of sensors for testing, to achieve the control of the functional modules to complete the design of the intelligent home environment monitoring system. The system function structure is shown in Figure 1. 


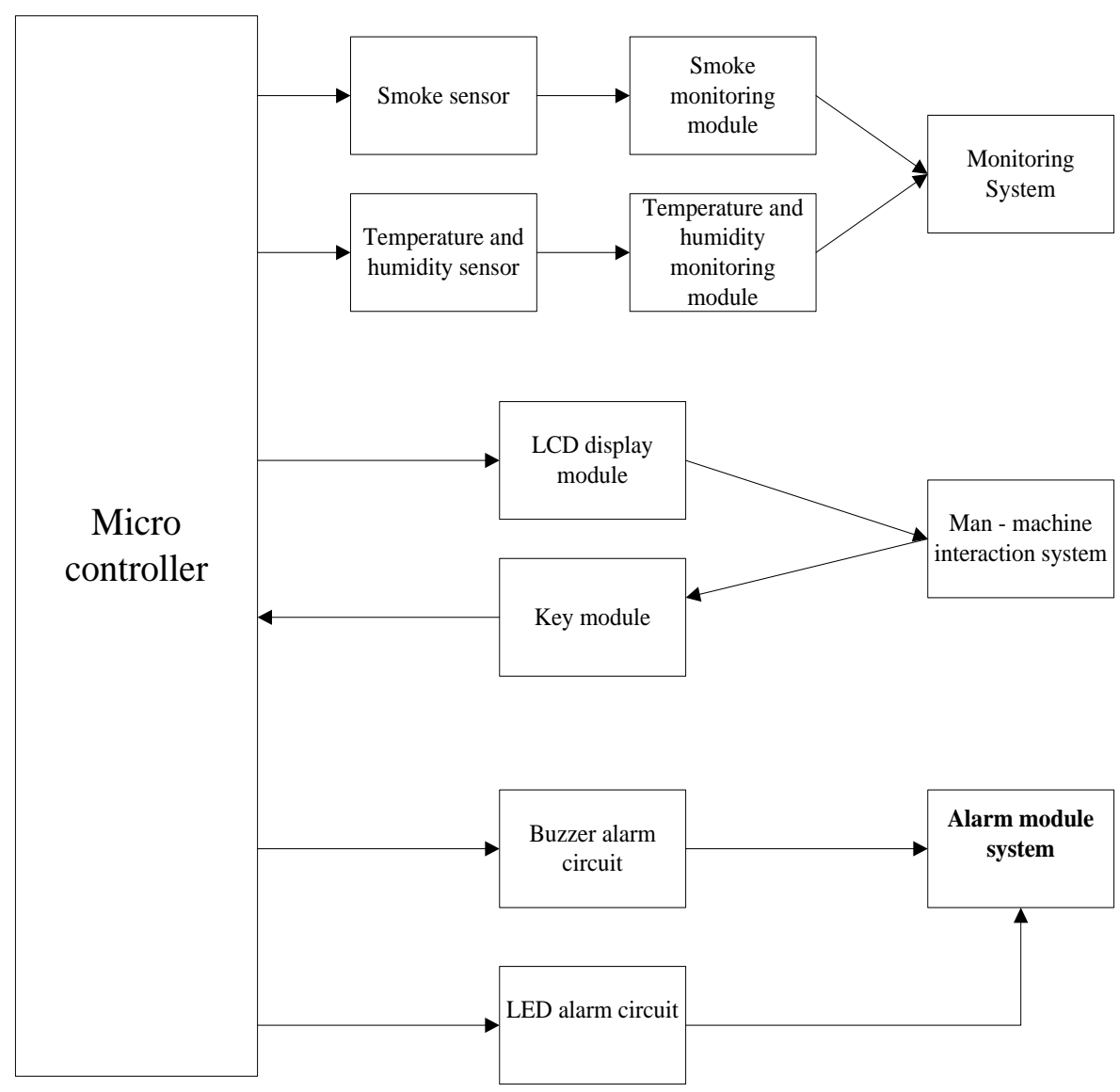

Figure1 The system function structure

\section{Hardware Design of The System}

\subsection{Overall Structural Design}

With the rapid development of sensor technology, industrial control technology and intelligent home technology, a variety of modular integrated circuits came into being, in order to improve design efficiency and shorten the development cycle, usually integrate a number of features and modules on a small monolithic chip ${ }^{[2]}$. The system uses low-power microcontroller STC89C52RC as the core controller, combined with environmental Sensing Sensors, LCD Monitors, Buzzer alarm device and so on, to achieve intelligent control of intelligent home environment monitoring system. The distribution design of structural module is shown in Figure 2.

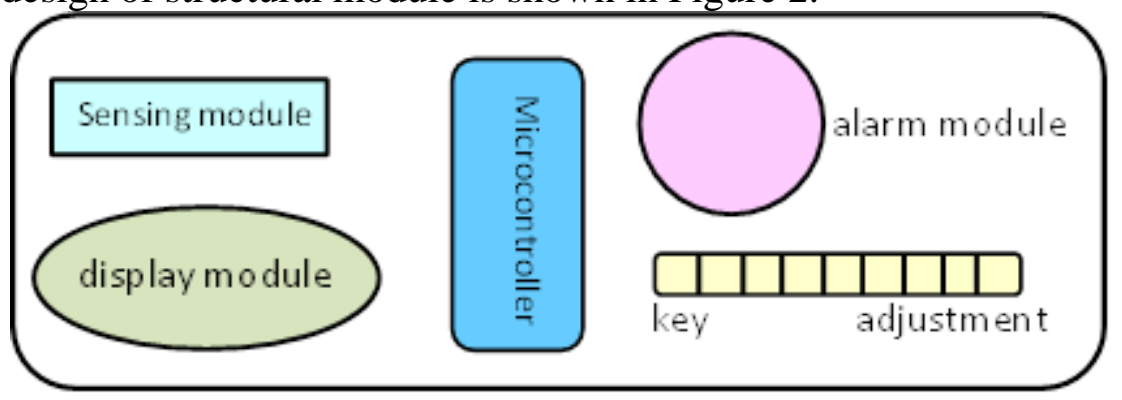

Figure2 The distribution design of structural module

\subsection{Hardware Circuit Design}

In view of the functional analysis of the system, the need to complete the circuit design of temperature and humidity monitoring module, smoke monitoring module, data acquisition module, 
display module, alarm module, key adjustment module. Due to limited space, take temperature and humidity monitoring module, smoke monitoring module as an example.

\subsubsection{The design of temperature and humidity sensing module}

Temperature and humidity sensing module selects DHT11 temperature and humidity sensors, connected pin 2 of DHT11 sensor and P3.7 port of the microcontroller, only use the I / O port can be connected with the microcontroller, P3.7 port used to send and receive serial data ${ }^{[3]}$. While the sensor's power supply ports Pin1 and Pin4 are respectively connected to the VCC and GND terminals of the microcontroller. The third foot of the sensor is suspended. The circuit of the DHT11 sensor and the microcontroller connected is shown in Figure 3.

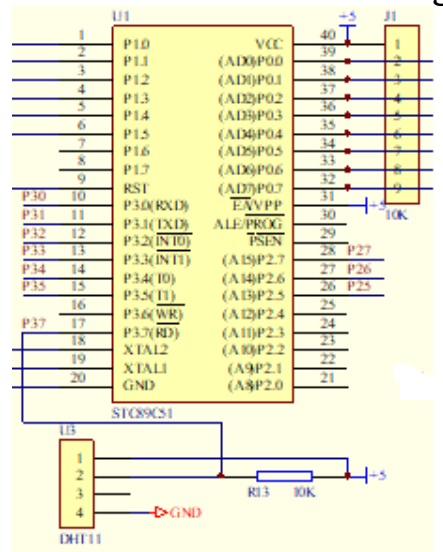

Figure3 temperature and humidity sensing module design

\subsubsection{The design of smoke monitoring module}

Smoke monitoring module selection MQ-2 as the detection of indoor smoke concentration and toxic gas sensor. MQ-2 contains six pins, divided into A, B and F feet of the two, A and B pins are used for signal output for grounding or power supply, Welding need to connect two A feet together, two B feet are also linked together, F for heating, one foot to ground, and the other with power ${ }^{[4]}$. The smoke monitoring module design is shown in Figure 4.

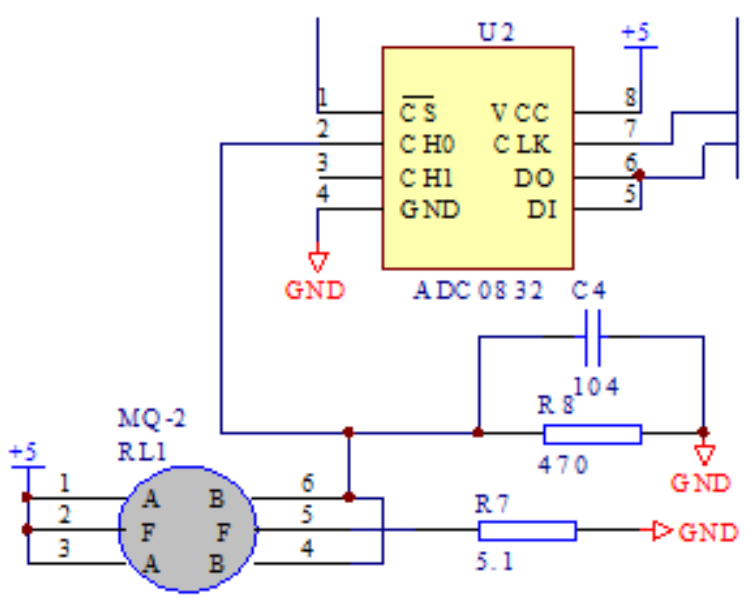

Figure4 The smoke monitoring module design

\section{Software Design of The System}

The design uses Keil C51 as a development tool, makse use of C language programming. Keil C51 integrates a large number of call sub-functions and function definition library. At the time of the call, the software can check the syntax error and prompt me to make changes. The user interface is friendly, powerful, and can generate HEX files. 
$\mathrm{C}$ language is one of the most widely used general computer programming language, is a highlevel language. $\mathrm{C}$ language compiler is simple, flexible and convenient, with a wealth of operators, data types. C language portability is good, with a program can be almost no modification, it applies to different single-chip platform, strong expression, the program readability is better. And it can run without the need for any operating environment support. C language is a structured language, with advantages of clear level, readability, please facilitate debugging and maintenance. $\mathrm{C}$ language has a wealth of operators and data types, and a variety of complex data structure operations can be achieved. More prominently, the $\mathrm{C}$ language is suitable for a variety of models and operating systems $^{[5]}$.

Software design requirements are easy to read, easy to maintain, accuracy and reliability. This requires the software designer to have a clear concept of the workflow of the entire control system, and an in-depth understanding of the functions of the control system. The software design of the control system follow the modular design principles, the function is designed as a subroutine for the main program calls to complete the control tasks. The system software framework is shown in Figure 5.

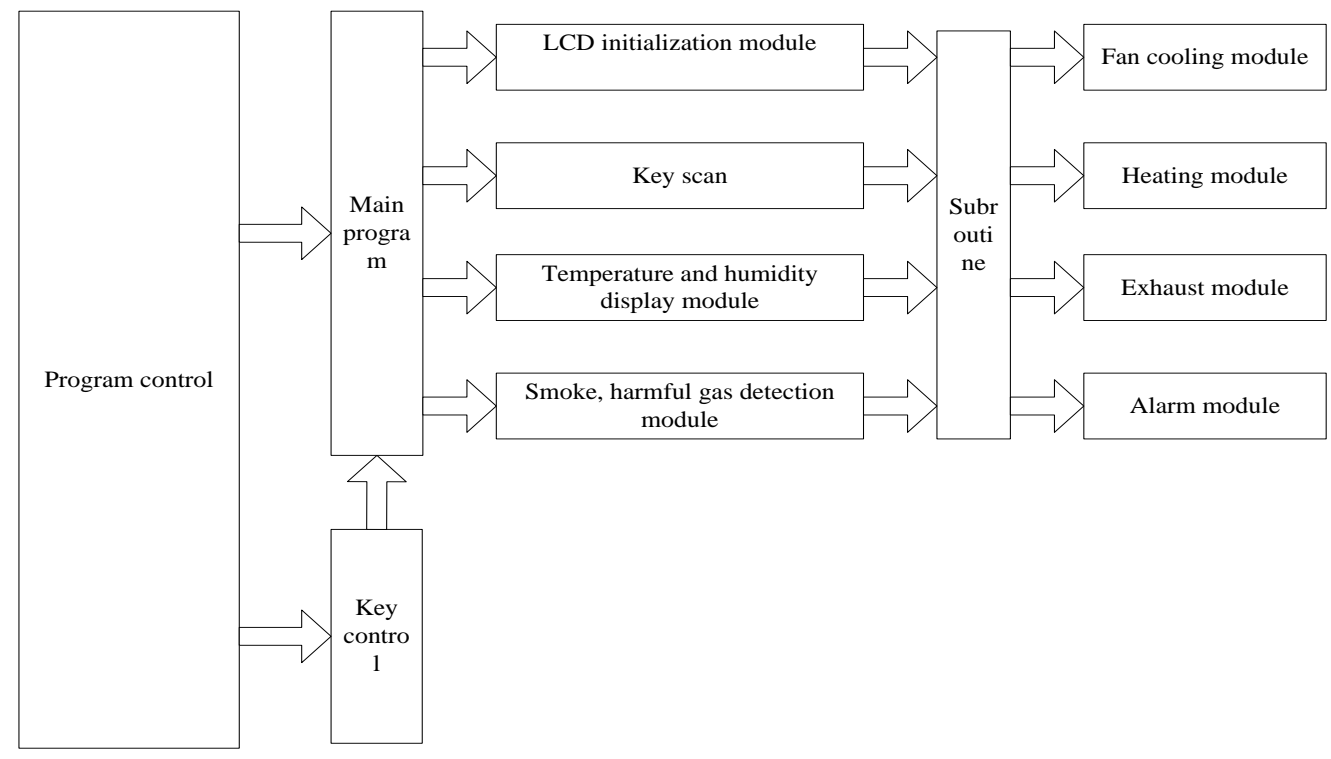

Figure4 The system software framework

\section{System Operation Results Analysis}

After the hardware circuit design, software programming, and the overall assembly and debugging, the intelligent home environment monitoring system has the fouction of temperature and humidity monitoring, smoke monitoring, data acquisition, displaying, alarm, key adjustment. Some of the operational results of the operation are analyzed as follows.

1.Analysis of operational Results of Temperature and Humidity Monitoring Module

The temperature and humidity values shown in the experiment are compared with the measured values of the standard hygrometer, which is shown in Table 1.

Table 1 Comparison of measured and theoretical values

\begin{tabular}{|c|c|c|c|c|}
\hline time(AM) & $\begin{array}{c}\text { DHT11 output } \\
\text { temperature value } \\
\left({ }^{\circ} \mathrm{C}\right)\end{array}$ & $\begin{array}{c}\text { DHT11 output } \\
\text { humidity value } \\
(\%)\end{array}$ & $\begin{array}{c}\text { Standard thermometer } \\
\text { value }\left({ }^{\circ} \mathrm{C}\right)\end{array}$ & $\begin{array}{c}\text { Standard hygrometer } \\
\text { value }(\%)\end{array}$ \\
\hline $6: 00$ & 20 & 41 & 20.2 & 42 \\
\hline $7: 00$ & 21 & 45 & 21.8 & 46 \\
\hline $8: 00$ & 21 & 47 & 22.1 & 47 \\
\hline $9: 00$ & 22 & 46 & 22.7 & 43 \\
\hline $10: 00$ & 24 & 43 & 23.8 & 42 \\
\hline $11: 00$ & 25 & 43 & 25.1 & 42 \\
\hline $12: 00$ & 27 & 41 & 27.4 & \\
\hline
\end{tabular}


The above table data analysis shows that Temperature and humidity sensor DHT11 measured values in line with the theoretical value.

2.operational Analysis of Multi - channel Acquisition Module for Air Quality

The results of the gas sensor in the experimental system were tested at a certain concentration as shown in Table 2.

Table 2 Measurement object and system response

\begin{tabular}{|c|c|c|c|c|c|}
\hline $\begin{array}{c}\text { the } \\
\text { Measured } \\
\text { object }\end{array}$ & MQ-2 & MQ-135 & $\begin{array}{c}\text { Buzzer } \\
\text { alarm }\end{array}$ & $\begin{array}{c}\text { LCD } \\
\text { display }\end{array}$ & $\begin{array}{c}\text { ventilato } \\
\text { r }\end{array}$ \\
\hline $\begin{array}{c}\text { Normal } \\
\text { air }\end{array}$ & $\times$ & $\times$ & No work & good & No work \\
\hline smoke & $\sqrt{ }$ & $\sqrt{ }$ & work & warn! & work \\
\hline gas & $\sqrt{ }$ & $\sqrt{ }$ & work & warn! & work \\
\hline $\begin{array}{c}\text { natural } \\
\text { gas }\end{array}$ & $\sqrt{ }$ & $\sqrt{ }$ & work & warn! & work \\
\hline $\begin{array}{c}\text { Liquefie } \\
\text { d gas }\end{array}$ & $\sqrt{ }$ & $\sqrt{ }$ & work & warn! & work \\
\hline $\begin{array}{c}\text { Ammoni } \\
\text { a }\end{array}$ & $\times$ & $\sqrt{ }$ & work & warn! & work \\
\hline Sulfide & $\times$ & $\sqrt{ }$ & work & warn! & work \\
\hline $\begin{array}{c}\text { Benzene } \\
\text { steam }\end{array}$ & $\times$ & $\sqrt{ }$ & work & warn! & work \\
\hline
\end{tabular}

The above table data analysis shows that the system is to meet the air quality testing, and using MQ-2 and MQ-135 to achieve the system's multi-channel acquisition function, for different environmental scenarios can choose the appropriate sensor for simultaneous detection. In the environment, using MQ-2 and MQ-135 at the same time can improve the detection sensitivity and reliability.

\section{Conclusions}

In the design , STC89C51 microcontroller as the core, Using DHT11 digital chip to do real-time monitoring of temperature and humidity, smoke sensors and air quality sensors to achieve the detection of air quality, and according to the set value to make the relevant alarm. The intelligent home environment monitoring system is a low-cost, low power consumption, easy to use, suitable for family.

\section{References}

[1]IWang Juan, Wei Xiong. Design of embedded intelligent home remote control system [J]. Technology Square, 2012 (5): 99-101.

[2] GS Gupta,SC Mukhopadhyay.Embedded Microcontroller Interfacing:Designing Integrated Projects[M]. Springer-Verlag Berlin Heidelberg,2010:79-98.

[3] Wu Jinshu, Shen Qingyang, Guo Tingji. 8051 single chip microcomputer practice and application [M]. Beijing: Tsinghua University Press, 2012.

[4] Zhang yigang Single Chip Microcomputer Principle and Interface Technology (C51 Programming) M].Beijing: People's Posts and Telecommunications Press, 2011: 323-325.

[5]Tan Haoqiang. C programming [M]. Beijing: Tsinghua University Press, 2010: 100-150. 